This is a pre-print (author's version). This article has been accepted for publication in Behavioral Ecology (BE), published by Oxford University Press.

BE first published July 6, 2021. https://doi.org/10.1093/beheco/arab047

Publisher copy available at https://academic.oup.com/beheco/advancearticle/doi/10.1093/beheco/arab047/6315972

\title{
Social insect colonies are more likely to accept unrelated queens when they come with workers
}

Ornela De Gasperin*, Pierre Blacher* \& Michel Chapuisat

*Co-first authors

Department of Ecology and Evolution,

University of Lausanne,

Lausanne, Switzerland

\section{Correspondence:}

Pierre Blacher and Ornela De Gasperin

E-mail: pierre.blacher@unil.ch,ornela.degasperin@unil.ch, 


\begin{abstract}
Relatedness underlies the evolution of reproductive altruism, yet eusocial insect colonies occasionally accept unrelated reproductive queens. Why would workers living in colonies with related queens accept unrelated ones, when they do not gain indirect fitness through their reproduction? To understand this seemingly paradox, we investigated whether acceptance of unrelated queens by workers is an incidental phenomenon resulting from failure to recognize non-nestmate queens, or whether it is adaptively favored in contexts where cooperation is preferable to rejection. Our study system is the socially polymorphic Alpine silver ant, Formica selysi. Within populations some colonies have a single queen, and others have multiple, sometimes unrelated, breeding queens. Social organization is determined by a supergene with two haplotypes. In a first experiment we investigated whether the number of reproductive queens living in colonies affects the ability of workers at rejecting alien queens, as multiple matrilines within colonies could increase colony odor diversity and reduce workers' recognition abilities. As workers rejected all alien queens, independently of the number of queens heading their colony, we then investigated whether their acceptance is flexible and favored in specific conditions. We found that workers frequently accepted alien queens when these queens came with a workforce. Our results show that workers flexibly adjust their acceptance of alien queens according to the situation. We discuss how this conditional acceptance of unrelated queens may be adaptive by providing benefits through increased colony size and/or genetic diversity, and by avoiding rejection costs linked to fighting.
\end{abstract}

Keywords: cooperation, recognition, mutualism, social polymorphism, supergenes, ants 


\section{Background}

Reproductive altruism was a challenge for evolutionary theory for decades. How does a gene that makes an individual sacrifice its own reproduction spread in a population? This paradox was solved by W. D. Hamilton, who showed that altruistic alleles can spread when the cost of altruism to the actor is smaller than the benefit to the recipient weighted by the level of genetic relatedness between them (Hamilton, 1963, 1964a). High relatedness antecedes the evolution of cooperating cellular units (Fisher et al., 2013), of cooperative breeding in birds (Cornwallis et al., 2010), and of the sterile worker caste in eusocial species (Hughes et al., 2008). Yet despite relatedness being fundamental for the evolution of reproductive altruism, eusocial species have repeatedly evolved social structures that decrease relatedness between colony members. In about $44 \%$ of all ant species, colonies accept additional reproductive queens (Boomsma et al., 2014). This process leads to 'secondary polygyny', which can be facultative or obligate and is hereafter referred to as 'polygyny'. Although queens in polygynous nests are typically related to one another, colonies sometimes adopt unrelated queens (Field and Leadbeater, 2016; Goodisman and Ross, 1999; Seppä, 1996; Stille and Stille, 1992; Zinck et al., 2007). This phenomenon is puzzling as workers and resident queen(s) do not gain indirect fitness benefits through the reproduction of unrelated queens. Why then, would they accept these queens in their nest?

Accepting alien queens can be beneficial when the direct fitness benefits of doing so exceed the costs (i.e. when the interaction is mutualistic; (West et al., 2021; West et al., 2007)). Mutualism is widespread across the tree of life, having been described in mammals, fish, birds, bacteria, amoeba, viruses, plants and arthropods, to name a few (reviewed in: (Boucher, 1985; Bronstein, 1994; Mesterton-Gibbons and Dugatkin, 1992; Roossinck, 2011; West et al., 2021)). Mutualism also occurs in eusocial insects, like when unrelated young queens associate (usually temporarily) to start a nest (Bernasconi and Strassmann, 1999; Eriksson et al., 2019; Johnson, 
2004; Offenberg et al., 2012; Trunzer et al., 1998). Similarly, individuals living in queenright colonies (i.e. colonies containing reproductive queens) can benefit from accepting alien queens when doing so increases colony size and/or colony genetic diversity. Larger colonies usually have better nest thermoregulation (Jones and Oldroyd, 2006; Kadochová and Frouz, 2013; Korb, 2003) and foraging efficiency (Donaldson-Matasci et al., 2013), increased division of labor (Ferguson-Gow et al., 2014; Holbrook et al., 2011), and better defense abilities against competitors, predators and brood raiders (Eriksson et al., 2019). And increased genetic diversity can improve colony immunity (Hughes and Boomsma, 2004; Schmid-Hempel and Crozier, 1999; Seeley and Tarpy, 2007), colony homeostasis (Oldroyd and Fewell, 2007) and foraging efficiency (Mattila and Seeley, 2007). Hence, accepting alien queens may benefit workers if their presence increases the survival and reproductive success of queens to which they are related. However, the acceptance of unrelated queens need not be beneficial to the host queen and workers and may result from failures in recognition systems of workers (Adams et al., 2007; Reeve, 1989; Suarez et al., 2020; Vander Meer and Morel, 1998).

Nestmate recognition in social insects is based on the detection of non-volatile chemicals cues, mostly long chain hydrocarbons present on their cuticle (cuticular hydrocarbons or CHCs; (d'Ettorre and Lenoir, 2010; van Zweden and d'Ettorre, 2010). The exchange of $\mathrm{CHCs}$ among colony members leads to the formation of a specific colony odor that allows individuals to recognize nestmates (d'Ettorre and Lenoir, 2010; Hefetz, 2007; Sturgis and Gordon, 2012; Vander Meer and Morel, 1998). Similarities in the odor profiles of colonies can lead to the erroneous acceptance of alien individuals (Reeve, 1989; Suarez et al., 2020). For example, in the invasive Argentine ant, Linepithema humile, workers and queens freely intermix between colonies that have similar cuticular hydrocarbon profiles (Pedersen et al., 2006; Suarez et al., 2002; Vásquez and Silverman, 2008). Recognition errors might be more frequent in polygynous colonies, as the presence of multiple matrilines increases genetic 
diversity and broadens the colony odor template (Adams et al., 2007; Reeve, 1989; Starks et al., 1998; Suarez et al., 2020). In support of this hypothesis, workers from polygynous species are often less aggressive towards alien individuals than workers from monogynous species (i.e. species with a single reproductive queen) (Vander Meer and Morel, 1998). And aggressiveness towards non-nestmate individuals co-varies negatively with colony queen number in Pseudomyrmex pullidus (Starks et al., 1998). Polygynous colonies may hence accept alien queens more frequently than monogynous ones, not because the presence of these queens directly benefits the colony members, but because workers fail to recognize them as nonnestmates.

Here, we investigate whether workers living in polygynous colonies are more prone to accepting alien queens due to a lower ability to recognize non-nestmate queens, or if their acceptance is favored in contexts where cooperation is preferable over rejection. Our model species is the socially polymorphic Alpine silver ant, Formica selysi, which typically nests underneath rocks along rivers in Alpine valleys in France, Italy and Switzerland (Purcell et al., 2015; Zahnd et al., 2021). This species forms dense populations with many colonies in close proximity to one another (Zahnd et al., 2021). Within populations, some colonies are monogynous (i.e. have a single reproductive queen), and others polygynous (i.e. have multiple reproductive queens; Chapuisat et al., 2004; Purcell et al., 2015). The two types of colonies exhibit alternative phenotypes, as the former has on average 3,000 workers and a lifespan of 10 years, whereas the latter has on average 30,000 workers and a lifespan of 30 years (Rosset and Chapuisat, 2007). Moreover, queens and workers produced by and living in monogynous colonies are larger than those from polygynous colonies (Meunier and Chapuisat, 2009; Rosset and Chapuisat, 2007; Schwander et al., 2005).

Social organization in F. selysi is determined by a supergene with two non-recombining haplotypes, $M$ and $P$ (previously called Sm and Sp, respectively; Avril et al., 2019; Purcell et 
al., 2014). All mature monogynous colonies are headed by one $M M$ queen mated to one or two $M$ males (males are haploid). These colonies do not host additional queens. Hence, all workers and queens in monogynous colonies have $M M$ supergene genotype. In contrast, all queens heading polygynous colonies have at least one copy of the $P$ haplotype (Avril et al., 2019; Purcell et al., 2014), producing workers and gynes that have either $M P$ or $P P$ supergene genotype. The effective number of queens in polygynous colonies is 4.3 (Chapuisat et al., 2004).

Polygynous colonies in the wild host related and some unrelated reproductive queens, and the mechanisms accounting for the presence of the latter remain unknown. The relatedness between nestmate queens within polygynous colonies, although significantly higher than zero, is low and variable $(\mathrm{r}=0.179 \pm 0.018$; mean $\pm \mathrm{SE}$; range $=0-0.9$; Avril et al., 2019). Out of 179 pairs of nestmate queens, $67(37 \%)$ were unrelated $(\mathrm{r}=0)$, and $96(53 \%)$ had relatedness estimates below 0.1 (pairwise relatedness estimates obtained from data in Avril et al., 2019, using the method described in Huang et al., 2015). High relatedness between nestmate queens suggests that daughter-queens are re-accepted in their maternal nest, as occurs in many polygynous species (Bourke and Franks, 1995). By contrast, very low relatedness between pairs of nestmate queens suggests that some unrelated, alien queens are accepted, as also happens in other polygynous species (Goodisman and Ross, 1999; Seppä, 1996; Stille and Stille, 1992; Zinck et al., 2007). Yet in the laboratory, monogynous and polygynous workers living without a queen reject all alien mated queens (Meunier et al., 2011b), and workers also recognize nonnestmate workers in the field (Rosset et al., 2007), probably via CHCs (Meunier et al., 2011a). The rejection of alien queens by polygynous workers raises the question of which mechanism accounts for the presence of alien queens in wild polygynous nests.

In controlled behavioral experiments, we investigated the mechanisms underlying the acceptance of alien queens by $F$. selysi workers living in queenright colonies. We focused on 
polygynous workers, as monogynous colonies do not host extra reproductive queens in nature, and we therefore expect monogynous colonies to reject all alien queens. First, we assessed whether the presence of multiple matrilines within colonies accounts for alien queen acceptance. Once we discovered that the number of reproductive queens in a nest does not affect whether polygynous workers accept or reject alien queens, we carried out a second experiment to investigate whether their acceptance could be favored in some conditions. Specifically, we tested whether polygynous workers were more likely to accept alien queens when they were accompanied by daughter-workers than when they were alone. Given the spatial proximity of colonies, regular behavioral interactions might result in mutual acceptance and fusion of colonies in the wild, but this possibility has not been evaluated yet. Accepting alien queens that come with a workforce could be beneficial, particularly for small colonies, because it allows them to quickly increase colony size and colony genetic diversity (see above). Furthermore, rejecting alien queens accompanied by workers could be more costly than rejecting lone queens, as the former could readily defend themselves and kill the host. Therefore, we predicted that polygynous workers would be more likely to accept alien queens when these queens came with daughter-workers than when they were alone.

\section{General methods}

\section{Experiment one: does polygyny affect the recognition abilities of workers?}

\subsection{Collection of host colonies}

We collected fragments of mature field colonies containing reproductive queens from a wellstudied population in Finges, Valais, Switzerland (46.3138 ${ }^{\circ}$, $7.6012^{\circ}$ E; 400m a.s.1.). During spring, queens come to the top of their colonies to warm up and resume egg laying. We collected workers and queens from monogynous and polygynous colonies using tweezers, between March and May 2018. Straight after collecting these colony fragments, we used a SNPs 
genotyping qPCR assay to determine the supergene genotype of three workers per colony and infer the social form of their colonies (Foncuberta et al.). In each monogynous colony we collected the single queen, whereas in each polygynous colony we sampled between one and eight queens. As some queens might have remained below ground, the number of queens collected in polygynous colonies was probably below (but likely proportional to) the real number of queens living in these colonies. We placed each colony fragment inside a plastic box $(26 \times 17 \times 13.5 \mathrm{~cm})$, lined with fluon, and with a glass tube (length $=16 \mathrm{~cm} ; \varnothing=5 \mathrm{~mm}) 1 / 3$ filled with water. We kept the colonies in the laboratory for 14 months before the start of the acceptance experiments, so that the sampled queens had time to produce daughter-workers. Between May and October 2018, colonies were kept at $25^{\circ} \mathrm{C}, 70 \%$ humidity, in a light:dark 12:12 hours cycle, with food in the form of egg and apple jelly ad libitum. Between November 2018 and April 2019, the period of hibernation in nature, we kept colonies at $8^{\circ} \mathrm{C}, 70 \%$ humidity and in a light:dark 12:12 hours cycle, without food.

\subsection{Collection and experimental mating of alien queens}

In June 2019, we collected sexual pupae and workers from a different set of field colonies from the same population. We determined the social form of these colonies by qPCR assays, as described above. We kept the pupae and workers from each colony inside a plastic box $(15.5 \mathrm{x}$ $13.5 \times 5.5 \mathrm{~cm})$, lined with fluon, and with a glass tube (length $=16 \mathrm{~cm} ; \varnothing=5 \mathrm{~mm}){ }^{1 / 3}$ filled with water. We kept these colony samples in standard laboratory conditions, at $25^{\circ} \mathrm{C}, 70 \%$ humidity and in a light:dark 12:12 hours cycle, and fed them twice a week with egg and apple jelly. Emerging queens and males were separated regularly to prevent them from mating. Young queens were placed to mate in artificial swarms alongside non-nestmate males, within plastic boxes (height $=20 \mathrm{~cm}$; length at the top $=42 \mathrm{~cm}$; width at the top $=26.5 \mathrm{~cm}$ ), covered with a mesh and placed under direct sunlight. We collected any mating pair and, four hours after mating, we introduced the queens into their host colony (see below). 


\subsection{Introduction of alien queens into host colonies}

At least two weeks before the experiment (in June 2019) we placed inside each colony a petri dish divided in two by a mesh and closed with a cover drilled with small holes (Figure 1a). The set-up allowed workers to move freely in and out of the petri dish but prevented queens from entering it, exiting it, or moving between the compartments inside the petri dish. At this point we counted all the workers and pupae of all colonies. Newly mated alien queens (see above) were introduced into three types of host colonies: i) polygynous colony fragments with a single queen $(\mathrm{N}=17)$; ii) monogynous colony fragments $(\mathrm{N}=18)$; and iii) polygynous colony fragments with multiple queens $(\mathrm{N}=18)$. Host colonies were relatively small (median size of $210 ;$ range $=57-884)$, and of similar sizes $\left(\right.$ Kruskal-Wallis $\chi^{2}=2.99$; d.f. $=2 ; p=0.22$; median size of one-queen polygynous colonies $=234$, range $=57-884$; of monogynous colonies $=$ 285 , range $=100-830 ;$ and of multiple-queen polygynous colonies $=200$, range $=90-452$ ) Polygynous colony fragments with multiple queens had a median number of 3 queens (range $=$ $2-6)$

We introduced one newly mated alien polygynous queen (i.e. emerging from a multiplequeen colony) and one newly mated alien monogynous queen (i.e. emerging from a singlequeen colony) simultaneously into the petri-dish, randomly allocating each queen into one of the two compartments. Queens (alien and host) were individualized via paint-marking before the trials. We recorded the survival of alien queens $24 \mathrm{hrs}$ and $48 \mathrm{hrs}$ after introduction. To avoid disturbing the colonies we did not monitor queen survival more frequently, nor did we measure other behavioral variables.

\section{Experiment two: Is alien queen acceptance by polygynous workers conditional and} favored when queens come with workers?

Experiment two started after experiment one had finished. We used 46 of the 53 host colonies used for experiment one, plus 21 colonies that had been collected from the same population at 
the same time as those used for experiment one. These colonies had been kept in the same conditions, and we verified that the behavior of colonies used in both experiments did not differ from the one of colonies used in experiment two only (there was no statistical differences in the rates of alien queen acceptance and of queen mortality between the two groups of colonies, all $p>0.5$ ). In experiment two, each replicate consisted of a pair of colonies (or a colony paired to a lone alien queen), connected via a small foraging arena placed at equal distance of the two colonies (Figure 1b). We randomly chose the side where each colony (or queen) was placed. Each colony was connected to the foraging arena through a rubber tube $(\varnothing=5 \mathrm{~mm}$; length $=$ $4 \mathrm{~cm})$. We had three treatments, with the focal colony being always a polygynous colony fragment with workers. The focal colony was connected to either: i) another polygynous colony fragment with workers ('P-P' treatment; $\mathrm{N}=12$ ), ii) a monogynous colony fragment with workers ('P-M' treatment; $\mathrm{N}=15$ ), or to iii) a lone, newly mated, alien polygynous queen ('PSQ' treatment; $N=13$ ). Polygynous colony fragments with one queen or with multiple queens were distributed randomly across the three treatments $(4,8$, and 5 of the focal polygynous colonies had one queen, while 8,7 and 8 had multiple queens in the 'P-P', 'P-M' and 'P-SQ' treatment, respectively; 4 alien polygynous colonies had one queen and 8 had multiple queens in the 'P-P' treatment).

To acquire newly mated, lone alien polygynous queens (i.e. emerging from multiplequeen colonies), we followed the same procedure as described for experiment one, and again introduced them into the experiment four hours after mating. Again, we paint-marked queens of each colony before the trials, at the same time for all queens. We predicted that polygynous colonies would kill lone polygynous queens, as in experiment one, but that they would accept polygynous queens with workers (because they provide labor, or to avoid the costs of fighting), leading to the merging of colonies, with non-nestmate queens sharing the same nest. We also predicted that polygynous colonies would not merge with monogynous ones, because of 
intolerance of monogynous workers, and maybe also of polygynous workers (as monogynous colonies typically do not host extra reproductive queens and polygynous colonies hosting both queen types have not been found in nature; Purcell et al., 2014; Avril et al., 2019).

Observers naïve to the hypotheses and to the genotype of the queens and workers monitored the experiment twice a week for a month, unless all queens from one colony had died, in which case colonies were separated. At each observation they recorded for each queen whether she was dead or alive, and her spatial location (queens were allowed to move freely in this experiment), and they replaced the food in the foraging arena.

\section{Statistical analyses}

All analyses were carried out in R (R Core Team 2019) v. 3.6 .2 with generalized linear models ('glm' function, stats package; R Core Team 2019). We obtained model estimates with ANOVA type II sum of squares ('Anova' function; Fox et al., 2012), and estimates, standard errors (SE) and $p$ values with the 'summary' function (R Core Team 2019). We extracted posthoc estimates, SE, and adjusted $p$-values with false discovery rate 'FDR' correction ('1smeans' function; Lenth, 2016).

\subsection{Experiment one: does polygyny affect the recognition abilities of workers?}

All alien queens were killed within $48 \mathrm{hrs}$, but some were still alive after $24 \mathrm{hrs}$. We compared the probability that at least one alien queen survived the first $24 \mathrm{hrs}$ using logistic regression (1 $=$ at least one of the two alien queens survived; $0=$ no alien queen survived). We included as explanatory variable the treatment (with three levels: polygynous with a single queen, monogynous, or polygynous with multiple queens) and the size of the host colony as a continuous covariable. 


\subsection{Experiment two: Is alien queen acceptance by polygynous workers conditional and favored when queens come with workers?}

We evaluated the prediction that polygynous colonies would be more likely to accept alien polygynous queens with workers than without workers, or than monogynous queens with workers. To categorize whether alien queens were accepted or rejected, each alien queen received a score of 1 ('she was accepted') or of 0 ('she was rejected'). Alien queens received a score of 0 if they died or if they were observed in all or in the majority of observations inside a separate box than the one where focal queen(s) were living. Only alien queens that were alive at the end of the experiment and that had been observed in the same box as focal queens in the majority of observations were considered as accepted (no matter in which of the three boxes, because all queens could move freely between them). Note that within replicates some alien queens could have died and the rest could have been accepted by the focal colony.

Because no queen was accepted in the P-M treatment, we could not run a GLM with binomial error distribution. Therefore, we calculated an odds ratio with a Bayes prior (Perks, 1947) for each replicate to compare queen acceptance between treatments. The odds ratio was calculated as: $\log (($ number of alien queens accepted +1$) /($ number of alien queens rejected + 1)). We used this odds ratio as a response variable in a GLM with normal error distribution and included the treatment (with three levels) as explanatory variable.

Because several focal and alien queens died during the experiment, we additionally compared the mortality of focal and of alien queen(s) between treatments. We again calculated odds ratios with Bayes priors as described above (again, because no focal queen died in the PSQ treatment, we could not use a GLM with binomial error distribution) calculated as: log ((number of focal (or alien) queens dead +1$) /($ number of focal (or alien) queens alive +1$)$ ). We used these odds ratios as response variables in two GLMs with normal error distribution, and included in both models the treatment (with three levels) as explanatory variable. In the 
three models we included the number of queens heading the focal nests as a covariable but removed it from the minimal adequate models.

\section{Results}

\section{Experiment one: does polygyny affect the recognition abilities of workers?}

Polygynous workers (i.e. workers originating from multiple-queen colonies) were as efficient as monogynous workers (i.e. workers originating from single-queen colonies) at recognizing and killing alien queens, independently of whether these polygynous workers lived in colony fragments with one or with multiple queens (Figure 2). All alien queens were killed within $48 \mathrm{hr}$ (Figure 2c). Hence, rejection occurred irrespective of the social origin of the introduced alien queens, of the social origin of the host workers, and of the number of queens in the host colony. The probability that at least one alien queen survived $24 \mathrm{hrs}$ did not differ between the three types of host colonies $\left(\chi^{2}=0.16 ; p=0.91\right.$; Figure $\left.2 \mathrm{a}\right)$, but larger colonies were more likely to kill both queens within 24 hours $($ Estimate $=-0.01 ; \mathrm{SE}=0.007 ; t$ value $=-2.03 ; p=0.04 ;$ Figure 2b).

2. Experiment two: Is alien queen acceptance by polygynous workers conditional and favored when queens come with workers?

Polygynous colonies rejected all but one lone alien polygynous queen, but frequently accepted alien polygynous queens accompanied by workers (overall effect of the treatment: $\chi^{2}=14.31$; $p=0.0007 ;$ acceptance in the P-P vs. P-SQ treatments: Estimate $=0.78 ; \mathrm{SE}=0.26 ; z=3.02 ; p$ $=0.003$; Figure $3 \mathrm{a}$ ). Polygynous colonies never merged with monogynous ones, despite the fact that in these colonies queens were also accompanied by workers (acceptance in the P-M vs. P$\mathrm{P}$ treatments: Estimate $=-0.89 ; \mathrm{SE}=0.25 ; z=-3.54 ; p=0.001$; acceptance in the P-M vs. P$\mathrm{SQ}$ treatments: Estimate $=-0.10 ; \mathrm{SE}=0.24 ; z=-0.43 ; p=0.66$; Figure $3 \mathrm{a}$ ). 
The mortality of focal queens differed sharply between treatments (overall effect of the treatment on focal queen mortality: $\chi^{2}=29.75 ; p<0.0001$ ). Focal queens had higher chances of dying when encountering a monogynous colony with workers than when encountering alien polygynous queens with or without workers (mortality of focal queens in the P-M vs. P-P treatments: Estimate $=1.15 ; \mathrm{SE}=0.34 ; z=3.40 ; p=0.001$; mortality of focal queens in the in the P-M vs. P-SQ treatments: Estimate $=1.77 ; \mathrm{SE}=0.33 ; z=5.35 ; p<0.0001$; Figure $3 \mathrm{~b}$ ). Monogynous colonies killed all focal polygynous queen(s) within four days in 12 out of 15 replicates, independently of the number of queens in these colonies. The probability that focal queens died was as low when encountering a polygynous colony with workers than when encountering a lone alien polygynous queen (mortality of focal queens in the P-P vs. P-SQ treatments: Estimate $=0.62 ; \mathrm{SE}=0.35 ; z=1.77 ; p=0.076$; Figure $3 b)$.

The mortality of alien queens also differed sharply between treatments (overall effect of the treatment on alien queen mortality: $\chi^{2}=24.1 ; p<0.0001$ ). Having workers greatly increased the survival probabilities of the alien queen(s) (mortality of alien queens in the P-M vs. $\mathrm{P}-\mathrm{SQ}$ treatments: Estimate $=-0.80 ; \mathrm{SE}=0.24 ; z=-3.31 ; p=0.001 ;$ and in the P-P vs. P-SQ treatments: Estimate $=-1.23 ; \mathrm{SE}=0.25 ; z=-4.80 ; p<0.0001)$. Indeed, 11 out of 13 alien lone queens were killed after only four days. Alien queens in colonies with workers had similar probabilities of dying, independently of whether they were polygynous or monogynous (mortality of alien queens in the P-P vs. P-M treatments: Estimate $=0.43 ; \mathrm{SE}=0.25 ; z=1.72$; $p=0.085$; Fig $3 \mathrm{c}$ ). The number of focal queens did not correlate with probabilities of queen acceptance, nor with mortality of focal or alien queens (all $p>0.09$ ).

\section{Discussion}

Kin selection solved one of the greatest mysteries in evolutionary biology: the evolution of reproductive altruism (Hamilton, 1963, 1964a, b). When a gene makes an organism help close 
kin reproduce, it is passing on copies of itself into future generations through copies of itself present in others. Yet almost half of all known ant species have colonies with multiple reproductive queens (Boomsma et al., 2014), which can sometimes be unrelated (Goodisman and Ross, 1999; Seppä, 1996; Stille and Stille, 1992; Zinck et al., 2007). Why would workers living with related queens accept unrelated queens, as they do not gain indirect fitness through their reproduction? Our results help answer this question by showing that the adoption of alien queens does not result from recognition errors but occurs when accepting them is preferable to rejecting them. Hence, we show that acceptance of alien queens can be context-dependent, with colonies flexibly deciding whether to reject or to accept alien queens according to the costs and benefits of doing so.

Polygynous colonies (i.e. colonies with queens and workers originating from multiplequeen colonies) often accepted alien queens when these queens were accompanied by their daughter-workers. By contrast, most queens without workforce were killed within a few days. The acceptance of alien queens accompanied by workers may be a form of mutualism (West et al., 2021; West et al., 2007), where individuals from both colonies benefit from the association through increased colony size and/or increased genetic diversity. Across social insects larger colonies have better defense abilities against competitors and predators (Eriksson et al., 2019), improved nest thermoregulation (Jones and Oldroyd, 2006; Kadochová and Frouz, 2013; Korb, 2003), higher foraging efficiency (Donaldson-Matasci et al., 2013), and increased division of labor (Ferguson-Gow et al., 2014; Holbrook et al., 2011). Moreover, hosting more genetically diverse individuals within the nest may lead to higher foraging efficiency (Mattila and Seeley, 2007), better colony immunity (Hughes and Boomsma, 2004; Schmid-Hempel and Crozier, 1999; Seeley and Tarpy, 2007), and colony homeostasis (Oldroyd and Fewell, 2007). Therefore, the integration of numerous unrelated individuals into a colony may bring benefits to members of both colonies. 
The potential benefits of accepting alien queens with workers may have been particularly large for our experimental colony fragments, due to their small size compared to field colonies (mature polygynous colonies have on average 30,000 workers, Rosset and Chapuisat, 2007). But the benefits of increased colony size may not be linear and rather follow an inverted U shape, reaching an upper-limit and then decreasing (Kramer et al., 2014), as very large colony size may lead to food depletion (Bonal and M. Aparicio, 2008), inefficiencies in task performance (Michener, 1964) and/or reduced worker longevity (Blacher et al., 2017; Rueppell et al., 2009). Therefore, the potential benefits of increasing colony size by accepting unrelated individuals depend on the optimal colony size, which probably varies according to the amount of resources available, the number of reproductive queens in a nest and the level of competition with other colonies (e.g. Porter and Tschinkel, 1985). The importance of colony size (both in absolute terms and relative to the size of neighboring colonies) in the probability of accepting alien queens and their workers should thus be investigated by future work.

Alternatively, or additionally, tolerating alien queens when accompanied by workers may have been the 'best of a bad job', where peaceful cooperation was less costly than losing workforce and queens during fights with other colonies, as happened when encountering monogynous colonies. Cooperation resulting from the 'best of bad job' is frequent in nature, like when workers that have lost their queen adopt unrelated queens in their nest, which ensures successful rearing of the sexual brood that was present in the nest when the mother queen passed away (Gadau et al., 1998; Herbers, 1993), or when these workers join neighboring colonies and help rear the brood of queens to which they are slightly related (Kronauer et al., 2010). Overall, polygynous colonies may accept alien queens with workers due to the fitness benefits that come with extra workforce, if larger or genetically more diverse colonies are more productive and competitive, and/or to minimize the costs that could arise by attempting to reject these queens. Both mechanisms may influence the probability of accepting alien queens by polygynous 
workers, and disentangling their respective effects would be challenging. But independently of the relative importance of these two mechanisms, we suggest that individuals gained higher net benefits when adopting alien polygynous queens that came with workers, than when rejecting them.

Even though cooperation between alien individuals is widespread across the tree of life (Boucher, 1985; Bronstein, 1994; West et al., 2021), including within eusocial insects (e.g. (Bernasconi and Strassmann, 1999; Eriksson et al., 2019; Field and Leadbeater, 2016; Johnson, 2004; Offenberg et al., 2012; Queller et al., 2000; Trunzer et al., 1998), it is often difficult to disentangle whether eusocial insect colonies host alien queens because they failed to reject them due to constraints in their CHC-based nestmate recognition system (e.g. Reeve, 1989; Suarez et al., 2020; Vásquez and Silverman, 2008; see also Field and Leadbeater, 2016; Suarez et al., 2002), or because the benefits of accepting them outweighted the costs of rejecting them. As recognition cues have a heritable component (Adams, 1991; Gamboa et al., 1986; van Zweden et al., 2010), having many matrilines in a colony generally increases the diversity of recognition cues within the nest. This could in turn affect nestmate recognition mechanisms, generating a positive feedback loop between the number of reproductive queens in a colony and the probability of accepting alien queens. But in our experiments, workers from polygynous colonies were able to discriminate lone alien queens, and the number of reproductive queens in their nest did not co-vary with the probability of accepting these alien queens. Therefore, the presence of alien queens in wild polygynous colonies (Avril et al., 2019) is not caused by a lower ability of these workers at distinguishing non-nestmate queens (see also Meunier et al., 2011a), nor by a more permissive acceptance threshold due to wider diversity of odor cues in colonies with multiple matrilines.

To conclude, we found no evidence that polygyny decreases the ability of workers to recognize alien queens. Acceptance of alien queens in the Alpine silver ant is therefore unlikely 
to be an incidental phenomenon resulting from recognition errors. Instead, workers living in queenright colonies flexibly adjusted the decision of whether to accept or to reject alien queens (Sturgis and Gordon, 2012), and accepted them only when the direct benefits of doing so outweighed the costs of rejecting them. This form of cooperation can explain why unrelated reproductive queens are occasionally accepted by queenright colonies (Boomsma et al., 2014; Bourke and Franks, 1995; Goodisman and Ross, 1999; Seppä, 1996; Stille and Stille, 1992; Zinck et al., 2007), despite colony members not gaining indirect fitness benefits from their reproduction. 
Acknowledgments. We thank Sagane Dind, Solenn Sarton-Lohéac, Santiago Herce Castañón, Marjorie Labédan, Jason Buser and Christophe Lakatos for their help with laboratory work. We thank Emilie Snell-Rood and three anonymous reviewers for comments on a previous version of the manuscript.

Data accessibility. Analyses reported in this article can be reproduced using the data provided by De Gasperin et al. (2021).

Competing interests. We declare we have no competing interests.

Funding. This work was supported by the Swiss National Science Foundation (grant no. 31003A-173189). 


\section{Figures}
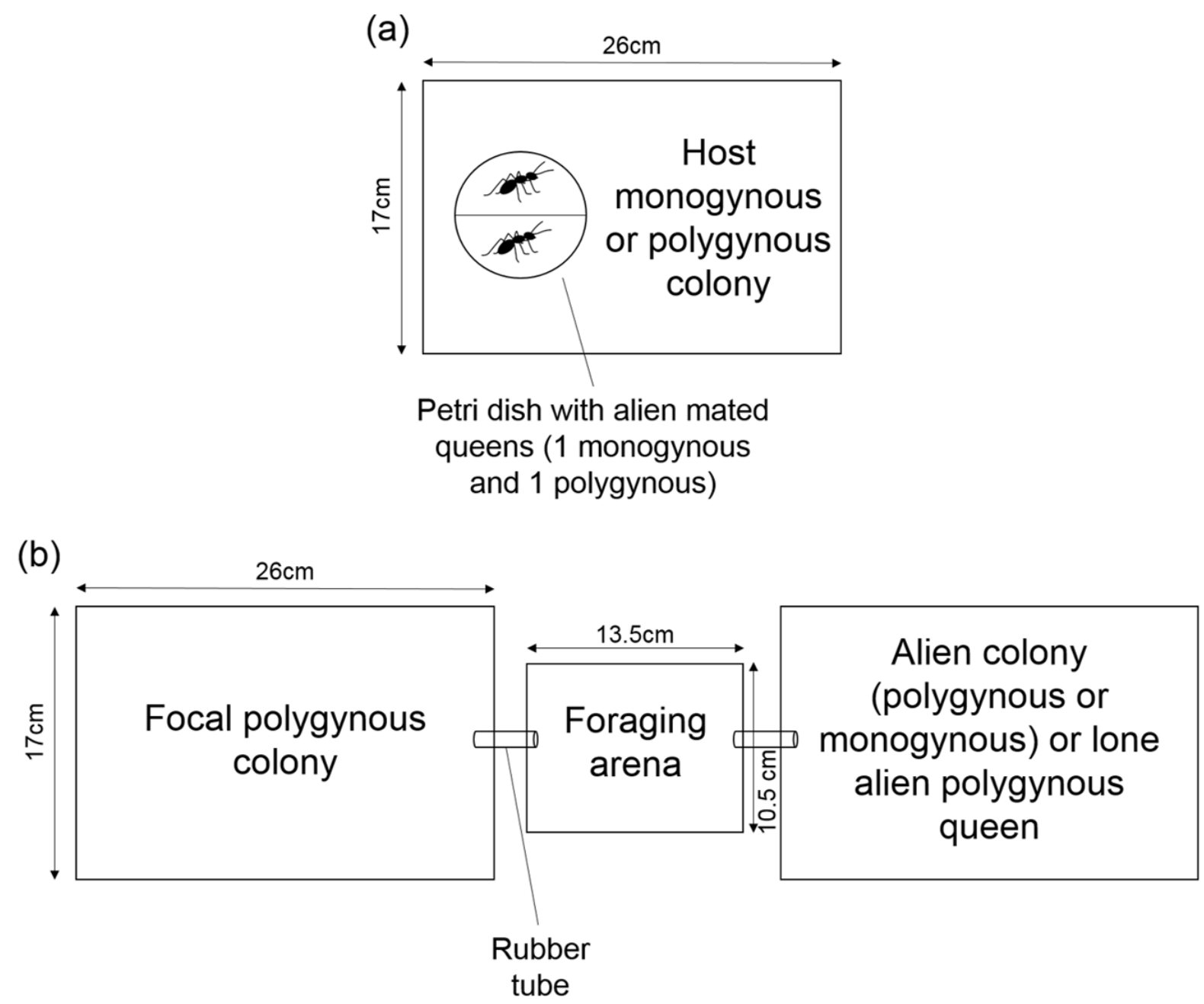

Figure 1. Experimental set-ups for experiment 1 (panel a) and experiment 2 (panel b). In experiment 1 , one newly mated alien monogynous queen (i.e. originating from a single-queen colony) and one newly mated alien polygynous queen (i.e. originating from a multiple-queen colony) were simultaneously introduced into a petri dish placed inside the host colony (host colonies: polygynous colony fragment with a single queen $(\mathrm{N}=17)$, monogynous colony fragment with a single queen $(\mathrm{N}=18)$, and polygynous colony fragment with multiple queens $(\mathrm{N}=18)$ ). In experiment 2 , one focal polygynous colony with workers was connected via a foraging arena to an alien colony with workers (polygynous $(\mathrm{N}=12)$ or monogynous $(\mathrm{N}=15))$ or to a lone alien mated polygynous queen $(\mathrm{N}=13)$. 

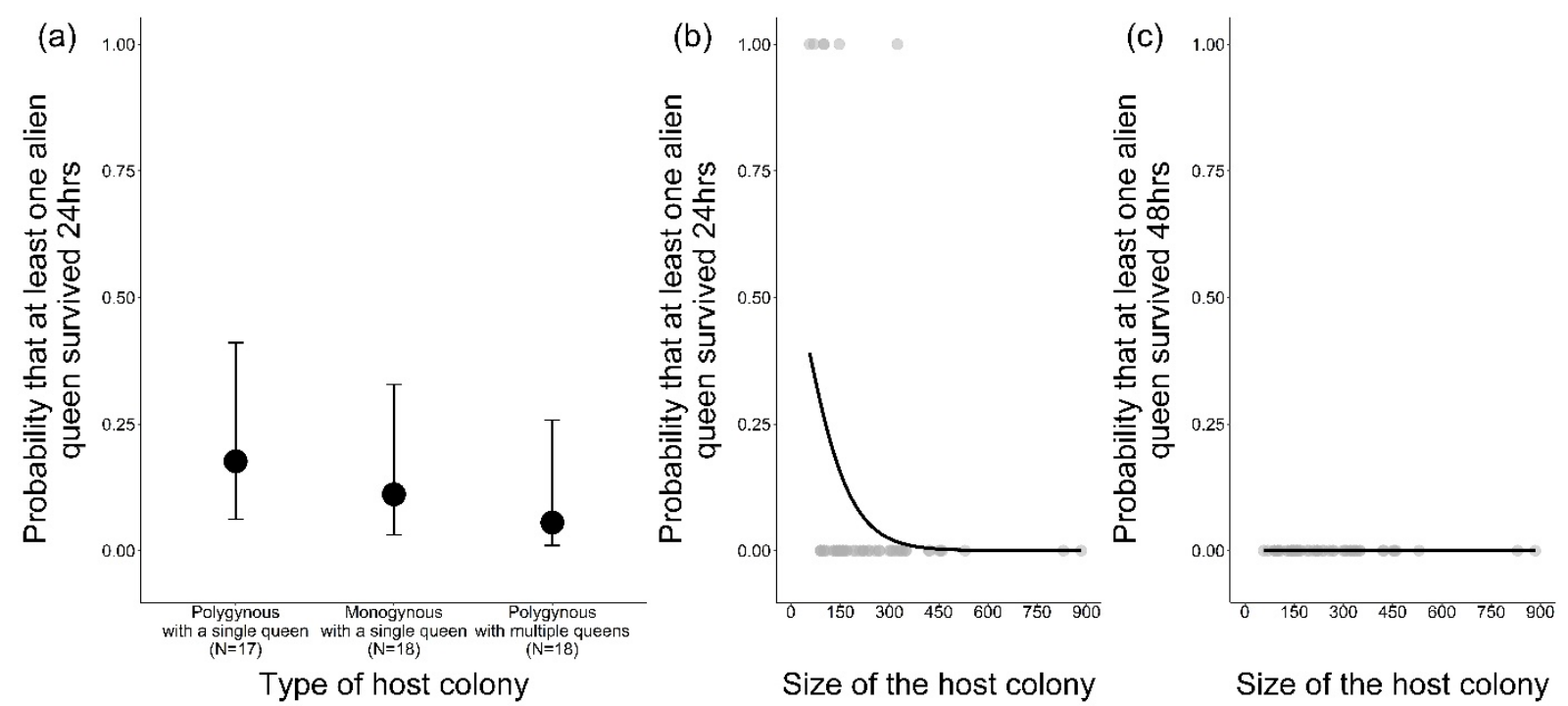

Figure 2. Polygynous and monogynous colonies reject lone alien queens (results from experiment 1). One newly mated alien polygynous queen and one newly mated alien monogynous queen were simultaneously introduced into either a polygynous colony with a single queen (i.e. queen and workers originating from multiple-queen colonies), a monogynous colony with a single queen, or a polygynous colony with multiple queens. Proportion of replicates where at least one alien queen survived for $24 \mathrm{hrs}$ after being introduced into the host colony, according to the type of host colony (panel a) and to the size of the host colony (panel b). Panel c shows the proportion of replicates where at least one alien queen survived for $48 \mathrm{hrs}$ after being introduced into the host colony according to the size of the host colony. Panel a shows the mean $\pm 95 \% \mathrm{CI}$, per type of host colony; panels $\mathrm{b}$ and $\mathrm{c}$ show the relation between the two variables. 

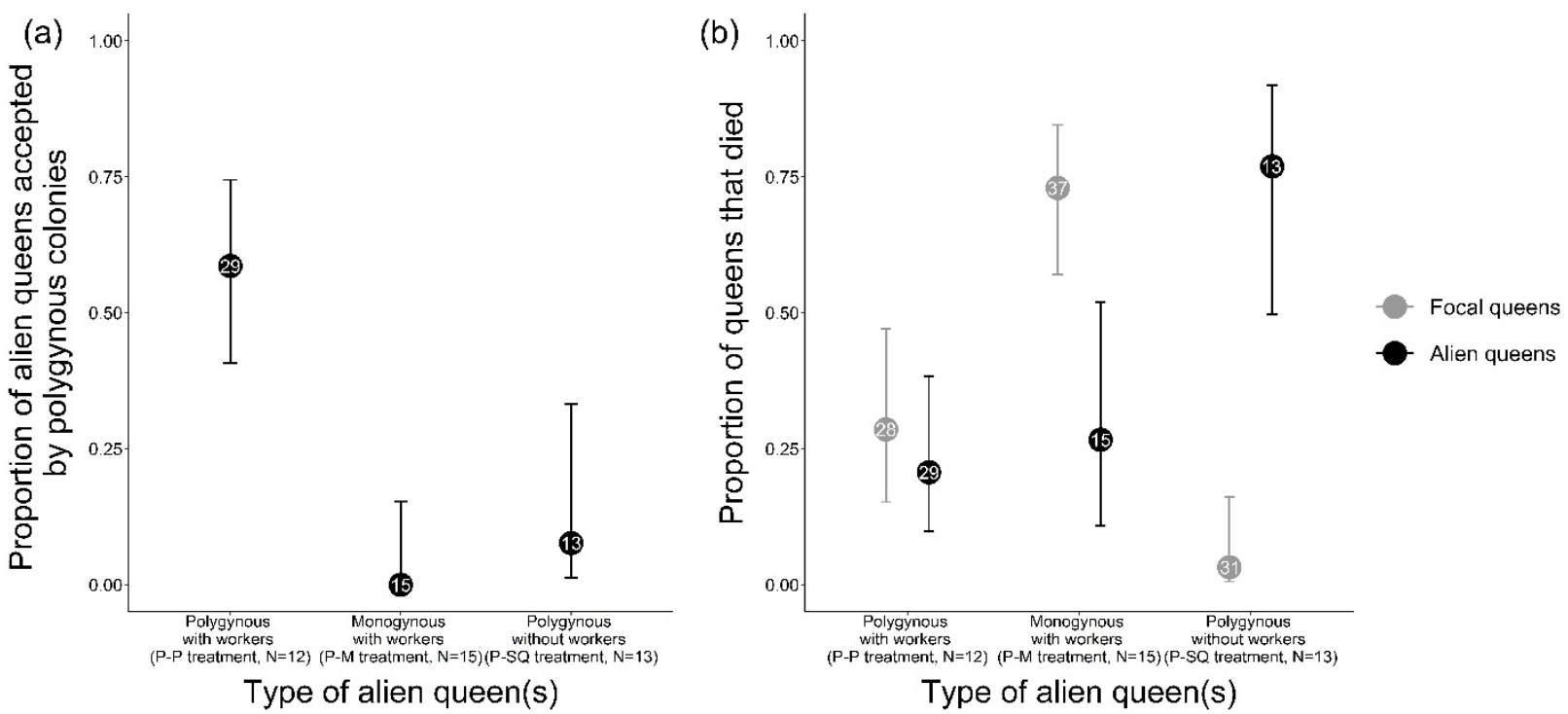

Figure 3. Polygynous colonies accept alien polygynous queens when they come with workers (results from experiment 2). Polygynous colonies (focal) were connected to either alien polygynous queen(s) with workers, an alien monogynous queen with workers, or to a newly mated, alien polygynous queen without workers. Panel a shows the proportion of alien queens accepted by polygynous colonies. Panel $b$ shows the proportion of focal and alien queens that died. Focal queens are shown in grey and alien queens in black. Focal queens had higher chances of dying when they encountered an alien monogynous queen with workers (P-M treatment). Almost all alien polygynous queens without workers died (P-SQ treatment). All graphs show the mean $\pm 95 \% \mathrm{CI}$, per treatment. $\mathrm{N}$ refers to the number of replicates (pairs of colonies), and the number inside the circles to the number of queens. 


\section{References}

Adams ES, 1991. Nest-mate recognition based on heritable odors in the termite Microcerotermes arboreus. Proc Natl Acad Sci U S A 88:2031-2034.

Adams ES, Atkinson L, Bulmer MS, 2007. Relatedness, recognition errors, and colony fusion in the termite Nasutitermes corniger. Behav Ecol Sociobiol 61:1195-1201. doi: $10.1007 / \mathrm{s} 00265-007-0349-7$.

Avril A, Purcell J, Brelsford A, Chapuisat M, 2019. Asymmetric assortative mating and queen polyandry are linked to a supergene controlling ant social organization. Mol Ecol 28:1428-1438.

Bernasconi G, Strassmann JE, 1999. Cooperation among unrelated individuals: the ant foundress case. Trends Ecol Evol 14(12):477-482. doi: doi:10.1016/S01695347(99)01722-X

Blacher P, Huggins TJ, Bourke AF, 2017. Evolution of ageing, costs of reproduction and the fecundity-longevity trade-off in eusocial insects. Proc R Soc Lond, Ser B: Biol Sci 284:20170380.

Bonal R, M. Aparicio J, 2008. Evidence of prey depletion around lesser kestrel Falco naumanni colonies and its short term negative consequences. J Avian Biol 39:189-197.

Boomsma JJ, Huszár DB, Pedersen JS, 2014. The evolution of multiqueen breeding in eusocial lineages with permanent physically differentiated castes. Anim Behav $92: 241-252$.

Boucher DH. 1985. The biology of mutualism: ecology and evolution. New York: Oxford University Press, New York.

Bourke AF, Franks NR. 1995. Social evolution in ants. Princeton University Press, Princeton, New Jersey.

Bronstein JL, 1994. Our current understanding of mutualism. Q Rev Biol 69:31-51. 
Chapuisat M, Bocherens S, Rosset H, 2004. Variable queen number in ant colonies: no impact on queen turnover, inbreeding, and population genetic differentiation in the ant Formica selysi. Evolution 58:1064-1072.

Cornwallis CK, West SA, Davis KE, Griffin AS, 2010. Promiscuity and the evolutionary transition to complex societies. Nature 466:969-972.

d'Ettorre P, Lenoir A, 2010. Nestmate recognition. Ant ecology:194-209.

De Gasperin O, Blacher P, Chapuisat M, 2021. Data from: Social insect colonies are more likely to accept unrelated queens when they come with workers. Behav Ecol. doi: https://doi.org/10.5061/dryad.t1g1jwt24.

Donaldson-Matasci MC, DeGrandi-Hoffman G, Dornhaus A, 2013. Bigger is better: honeybee colonies as distributed information-gathering systems. Anim behav 85:585592.

Eriksson T, Hölldobler B, Taylor J, Gadau J, 2019. Intraspecific variation in colony founding behavior and social organization in the honey ant Myrmecocystus mendax. Insectes Soc 66:283-297.

Ferguson-Gow H, Sumner S, Bourke AF, Jones KE, 2014. Colony size predicts division of labour in attine ants. Proc R Soc Lond, Ser B: Biol Sci 281:20141411.

Field J, Leadbeater E, 2016. Cooperation between non-relatives in a primitively eusocial paper wasp, Polistes dominula. Philos Trans R Soc Lond B Biol Sci 371:20150093. doi: doi:10.1098/rstb.2015.0093.

Fisher RM, Cornwallis CK, West SA, 2013. Group formation, relatedness, and the evolution of multicellularity. Curr Biol 23:1120-1125.

Foncuberta A, De Gasperin O, Dinde S, Avril A, Chapuisat M, Disentangling the mechanisms linking dispersal and sociality in supergene-mediated ant social forms. Proc R Soc Lond, Ser B: Biol Sci in press. 
Fox J, Weisberg S, Adler D, Bates D, Baud-Bovy G, Ellison S, Firth D, Friendly M, Gorjanc G, Graves S, 2012. Package 'car'. Vienna: R Foundation for Statistical Computing.

Gadau J, Gertsch PJ, Heinze J, Pamilo P, Hölldobler B, 1998. Oligogyny by unrelated queens in the carpenter ant, Camponotus ligniperdus. Behav Ecol Sociobiol 44:23-33.

Gamboa GJ, Reeve HK, Ferguson ID, Wacker TL, 1986. Nestmate recognition in social wasps: the origin and acquisition of recognition odours. Anim Behav 34:685-695.

Goodisman MA, Ross KG, 1999. Queen recruitment in a multiple-queen population of the fire ant Solenopsis invicta. Behav Ecol 10:428-435.

Hamilton WD, 1963. The evolution of altruistic behavior. Am Nat 97:354-356.

Hamilton WD, 1964a. The genetic theory of social behavior. I and II. J Theor Biol 7:1-52.

Hamilton WD, 1964b. The genetical evolution of social behaviour. II. J Theor Biol 7:17-52.

Hefetz A, 2007. The evolution of hydrocarbon pheromone parsimony in ants (Hymenoptera: Formicidae) - interplay of colony odor uniformity and odor idiosyncrasy. Myrmecol News 10:59-68.

Herbers JM. 1993. Ecological determinants of queen number in ants. In: Keller L, editor. Queen number and sociality in insects Oxford (439 p). New York: Oxford University Press, New York. p. 262-293.

Holbrook CT, Barden PM, Fewell JH, 2011. Division of labor increases with colony size in the harvester ant Pogonomyrmex californicus. Behav Ecol 22:960-966.

Huang K, Guo ST, Shattuck MR, Chen ST, Qi XG, Zhang P, Li BG. 2015. A maximumlikelihood estimation of pairwise relatedness for autopolyploids. Heredity, 114:133142.

Hughes WO, Oldroyd BP, Beekman M, Ratnieks FL, 2008. Ancestral monogamy shows kin selection is key to the evolution of eusociality. Science 320:1213-1216. 
Hughes WOH, Boomsma JJ, 2004. Genetic diversity and disease resistance in leaf-cutting ant societies. Evolution 58(6):1251-1260. doi: http://dx.doi.org/10.1111/j.00143820.2004.tb01704.X

Johnson RA, 2004. Colony founding by pleometrosis in the semiclaustral seed-harvester ant Pogonomyrmex californicus (Hymenoptera: Formicidae). Anim Behav 68:1189-1200. Jones JC, Oldroyd BP, 2006. Nest thermoregulation in social insects. Adv Insect Physiol 33:153-191.

Kadochová Š, Frouz J, 2013. Thermoregulation strategies in ants in comparison to other social insects, with a focus on red wood ants (Formica rufa group). F1000Research 2.

Korb J, 2003. Thermoregulation and ventilation of termite mounds. Naturwissenschaften 90:212-219. doi: 10.1007/s00114-002-0401-4.

Kramer BH, Scharf I, Foitzik S, 2014. The role of per-capita productivity in the evolution of small colony sizes in ants. Behav Ecol Sociobiol 68(1):41-53. doi: http://dx.doi.org/10.1007/s00265-013-1620-8

Kronauer DJ, Schöning C, d'Ettorre P, Boomsma JJ, 2010. Colony fusion and worker reproduction after queen loss in army ants. Proc R Soc Lond, Ser B: Biol Sci 277:755763.

Lenth RV, 2016. Least-squares means: the R package lsmeans. J Stat Softw 69:1-33.

Mattila HR, Seeley TD, 2007. Genetic diversity in honey bee colonies enhances productivity and fitness. Science 317:362-364.

Mesterton-Gibbons M, Dugatkin LA, 1992. Cooperation among unrelated individuals: evolutionary factors. Quarterly Rev Biol 67:267-281.

Meunier J, Chapuisat M, 2009. The determinants of queen size in a socially polymorphic ant. J Evol Biol 22:1906-1913. doi: 10.1111/j.1420-9101.2009.01805.x. 
Meunier J, Delémont O, Lucas C, 2011a. Recognition in ants: social origin matters. Plos One 6:e19347.

Meunier J, Reber A, Chapuisat M, 2011b. Queen acceptance in a socially polymorphic ant. Anim behav 81:163-168.

Michener CD, 1964. Reproductive efficiency in relation to colony size in hymenopterous societies. Insectes Soc 11:317-341.

Offenberg J, Peng R, Nielsen MG, 2012. Development rate and brood production in haploand pleometrotic colonies of Oecophylla smaragdina. Insectes Soc 59:307-311.

Oldroyd BP, Fewell JH, 2007. Genetic diversity promotes homeostasis in insect colonies. Trends Ecol Evol 22(8):408-413.

Pedersen JS, Michael JBK, Valérie V, Giraud T, Keller L, 2006. Native Supercolonies of Unrelated Individuals in the Invasive Argentine Ant. Evolution 60:782-791.

Perks W, 1947. Some observations on inverse probability including a new indifference rule. J Inst Act (1886-1994) 73:285-334.

Porter SD, Tschinkel WR, 1985. Fire ant polymorphism: the ergonomics of brood production. Behav Ecol Sociobiol 16(4):323-336. doi: doi:10.1007/BF00295545

Purcell J, Brelsford A, Wurm Y, Perrin N, Chapuisat M, 2014. Convergent genetic architecture underlies social organization in ants. Curr Biol 24:2728-2732. doi: 10.1016/j.cub.2014.09.071.

Purcell J, Pellissier L, Chapuisat M, 2015. Social structure varies with elevation in an Alpine ant. Mol Ecol 24(2):498-507. doi: http://dx.doi.org/10.1111/mec.13042

Queller DC, Zacchi F, Cervo R, Turillazzi S, Henshaw MT, Santorelli LA, Strassmann JE, 2000. Unrelated helpers in a social insect. Nature 405:784-787.

R Core Team. 2019. R: A language and environment for statistical computing. Vienna, Austria: R Foundation for Statistical Computing. 133. 
Reeve HK, 1989. The evolution of conspecific acceptance thresholds. Am Nat 133:407-435.

Roossinck MJ, 2011. The good viruses: viral mutualistic symbioses. Nat Rev Microbiol 9:99108.

Rosset H, Chapuisat M, 2007. Alternative life-histories in a socially polymorphic ant. Evol Ecol 21:577-588.

Rueppell O, Kaftanouglu O, Page Jr RE, 2009. Honey bee (Apis mellifera) workers live longer in small than in large colonies. Exp Gerontol 44:447-452.

Schmid-Hempel P, Crozier RH, 1999. Ployandry versus polygyny versus parasites. Philos Trans R Soc Lond B Biol Sci 354:507-515.

Schwander T, Rosset H, Chapuisat M, 2005. Division of labour and worker size polymorphism in ant colonies: the impact of social and genetic factors. Behav Ecol Sociobiol 59:215-221. doi: 10.1007/s00265-005-0027-6.

Seeley TD, Tarpy DR, 2007. Queen promiscuity lowers disease within honeybee colonies. Proc R Soc Lond, Ser B: Biol Sci 274:67-72. doi: doi:10.1098/rspb.2006.3702.

Seppä P, 1996. Genetic relatedness and colony structure in polygynous Myrmica ants. Ethol Ecol Evol 8:279-290. doi: doi:10.1080/08927014.1996.9522918

Starks PT, Watson RE, Dipaola MJ, Dipaola CP, 1998. The effect of queen number on nestmate discrimination in the facultatively polygynous ant Pseudomyrmex pallidus (Hymenoptera: Formicidae). Ethology 104:573-584.

Stille M, Stille B, 1992. Intra-nest and inter-nest variation in mitochondrial DNA in the polygynous ant Leptothorax acervorum (Hymenoptera: Formicidae). Insectes Soc 39:335-340. doi: doi:10.1007/BF01323953

Sturgis SJ, Gordon DM, 2012. Nestmate recognition in ants (Hymenoptera: Formicidae): a review. Myrmecol News 16:101-110. 
Suarez A, Scharf H, Reeve H, Hauber M, 2020. Signal detection, acceptance thresholds and the evolution of animal recognition systems. Phil Trans R Soc B 375: 20190464, 20190464.

Suarez AV, Holway DA, Liang D, Tsutsui ND, Case TJ, 2002. Spatiotemporal patterns of intraspecific aggression in the invasive argentine ant. Anim Behav 64(5):697-708. doi: doi:10.1006/anbe.2002.4011

Trunzer B, Heinze J, Hölldobler B, 1998. Cooperative colony founding and experimental primary polygyny in the ponerine ant Pachycondyla villosa. Insectes Soc 45:267-276.

van Zweden JS, Brask JB, Christensen JH, Boomsma JJ, Linksvayer TA, d'Ettorre P, 2010. Blending of heritable recognition cues among ant nestmates creates distinct colony gestalt odours but prevents within-colony nepotism. J Evol Biol 23(7):1498-1508. doi: http://dx.doi.org/10.1111/j.1420-9101.2010.02020.x

van Zweden JS, d'Ettorre P, 2010. Nestmate recognition in social insects and the role of hydrocarbons. In: Blomquist GJ, Bagnères AG, editors. Insect hydrocarbons: Biology, biochemistry, and chemical ecology Cambridge, New York: Cambridge University Press. p. 222-243.

Vander Meer RK, Morel L. 1998. Nestmate recognition in ants. In: Vander Meer RK, Breed M, Winston M, Espelie KE, editors. Pheromone communication in social insects. Boulder (CO): Westview Press, New York. p. 79-103.

Vásquez GM, Silverman J, 2008. Intraspecific aggression and colony fusion in the Argentine ant. Anim Behav 75(2):583-593. doi: doi:10.1016/j.anbehav.2007.06.019

West SA, Cooper GA, Ghoul MB, Griffin AS, 2021. Ten recent insights for our understanding of cooperation. Nat Ecol Evol 5, 419-430 https://doi.org/10.1038/s41559-020-01384-x 
West SA, Griffin AS, Gardner A, 2007. Evolutionary explanations for cooperation. Curr Biol 17:R661-R672.

Zahnd S, Fontcuberta A, Koken M, Cardinaux A, Chapuisat M, 2021. Fine-scale habitat heterogeneity favours the coexistence of supergene-controlled social forms in Formica selysi. BMC Evol Biol 21, 24.

Zinck L, Jaisson P, Hora RR, Denis D, Poteaux C, Doums C, 2007. The role of breeding system on ant ecological dominance: genetic analysis of Ectatomma tuberculatum. Behav Ecol 18:701-708. 